\title{
ICT-Based Health Care Services for People with Spinal Cord Injury: A Pilot Study
}

\author{
Wanho Jang ${ }^{1}$, Dongwan Kim ${ }^{1}$, Jeonghyun $\mathrm{Kim}^{2}$, Seungwan Yang ${ }^{3}$, \\ Yunjeong $\mathrm{Uhm}^{4}$, and Jongbae $\mathrm{Kim}^{5(\bowtie)}$ \\ ${ }^{1}$ Department of Occupational Therapy, The Graduate School, \\ Yonsei University, Seoul, South Korea \\ crewano@gmail.com, dwan3303@naver.com \\ ${ }^{2}$ Usability Center, Enabling Science Technology Research Center, \\ Yonsei University, Seoul, South Korea \\ otrehab486@gmail.com \\ 3 Yonsei Enabling Science and Technology Research Center, Seoul, \\ South Korea \\ shilover0@gmail.com \\ ${ }^{4}$ Department of Ergonomic Therapy, The Graduate School of Health and \\ Environment, Yonsei University, Seoul, South Korea \\ uyjot@naver.com \\ ${ }^{5}$ Department of Occupational Therapy, College of Health Science, \\ Yonsei University, Seoul, South Korea \\ jongbae@yonsei.ac.kr
}

\begin{abstract}
People with Spinal cord injuries are having difficulty in health care, and complications cause physical, social and economic losses. In severe cases, complications lead to death and require systematic management. In this study, ICT-based health care service was developed to manage the respiratory function and urinary function of the people with spinal cord injuries and to help adapt to daily living activities and social participation through home visit occupational therapy. A pilot study was conducted with five clients with spinal cord injuries to investigate the effectiveness of the intervention services. As a result, it was confirmed that satisfaction, importance, and difficulty were appropriate. In the future, RCT clinical studies will be needed to diversify intervention services and expand the number of patients.
\end{abstract}

Keywords: ICT-based health care service $\cdot$ Spinal cord injury $\cdot$ Health $\cdot$ Complication

\section{Introduction}

People with spinal cord injuries have impaired motor and sensory function and have difficulty in daily activities and social participation [1-3]. They participate in rehabilitation treatment in hospitals, and after discharge, suffer from complications [4]. Pressure ulcers may occur due to sensory impairment, and various complications such as respiratory diseases occur due to respiratory muscle function deterioration [5]. This can lead to difficulties in activity and participation and, in severe cases, to death [6, 7]. 
Complications, therefore, lead to many losses physically, socially, and economically [8]. In the Republic of Korea, $90.5 \%$ of those with spinal cord injuries reported complications. The main complications were cystitis, pressure sores, and pain. Most spinal cord injuries also report that complications are a major detriment to a healthy life [9]. Therefore, it is essential to prevent and systematically manage these complications. Traditionally, complications are managed regularly by a doctor at a hospital. However, people with spinal cord injuries have difficulty in accessing medical services due to the inconvenience of movement due to physical impairment and the economic burden on hospital expenses $[10,11]$. Therefore, recently, a service for managing health by using a remote system has been provided $[12,13]$. Telerehabilitation using information and communication technology refers to providing comprehensive medical services to patients who have difficulty in moving to medical facilities or who wish to rehabilitate at home $[14,15]$. Therefore, this study aims to verify the effectiveness of health management by providing ICT-based health care services for people with spinal cord injuries.

\section{Method}

\subsection{Participants}

From June 2019 to July 2019, we visited five families with spinal cord injury in the community and provided an ICT-based complication management system. The characteristics of the subjects were five males, and the mean onset duration was 21.8 years, four thoracic level injury and one lumbar level injury. The level of paralysis is five complete injuries.

\subsection{ICT-Based Health Care Services}

After using respiratory and urinary devices, and applying home visit occupational therapy, enter the data into a smart device or a desktop computer. If the doctor

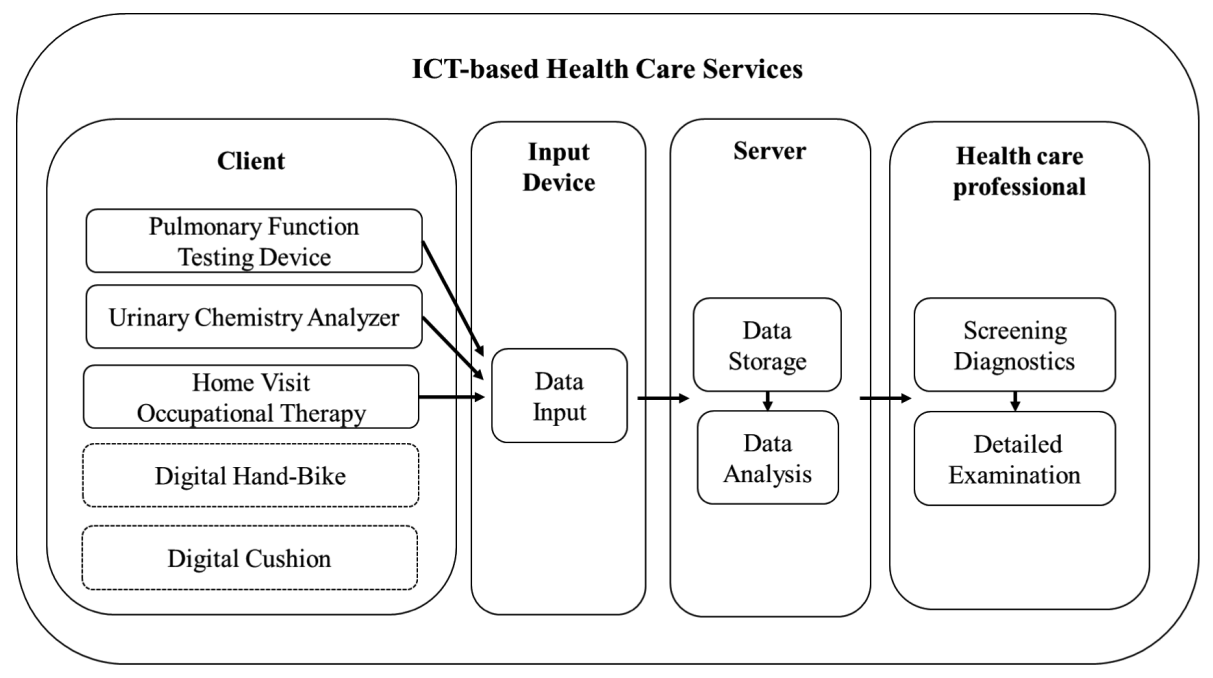

Fig. 1. ICT-based health care services 
determines that there is a problem with the patient, he or she will request a hospital visit. Digital hand bikes and digital cushions are currently in development (Fig. 1).

\subsection{Pulmonary Function Testing Device}

It is a device that can measure FEV1 (Forced Expiratory Volume in one second), PEF (Peak Expiratory Flow), and these are typical indicators of respiratory function [16]. The patient can measure it directly. Occupational therapists can be visited, trained, and assisted with the measurement as needed. This data will be stored on the server. If the doctor or occupational therapist determines that the client have a problem with a pulmonary function, ask to visit the hospital.

\subsection{Urinary Chemistry Analyzer}

A urine chemistry analyzer can be used to screen a total of 10 components, including glucose, protein, and white blood cells. The client's urine will be examined, or an occupational therapist will be available to help if needed. Data is stored on the server and can be accessed by doctors and occupational therapists. If an outlier is found, the client will be referred for a detailed examination.

\subsection{Home Visit Occupational Therapy}

The occupational therapist visits the home and performs occupational therapy to the client. Occupational therapy interventions consist of interventions in daily living activities, home environment modifications, self-exercise training, and range of motion exercises, assistive technology services, and community service information. The result data of the evaluation and treatment is input to the smart device, and the data is stored in the server.

\subsection{Digital Hand-Bike}

There is not much exercise equipment for people with cervical spinal cord injury. Therefore, we are currently developing a hand-bike for them (Fig. 2). Previous studies have reported that hand-bikes for people with spinal cord injuries help improve motor function and health [17]. This was excluded in this pilot experiment.

\subsection{Digital Cushion}

Pressure ulcers in people with spinal cord injuries are one of the most common complications [18]. The reason is caused by sensory paralysis of the lower extremities. Therefore, they need appropriate seating system intervention. We are making a customized cushion with pressure sensors (Fig. 2). It can monitor the pressure in real-time. This cushion was excluded from the current study. 

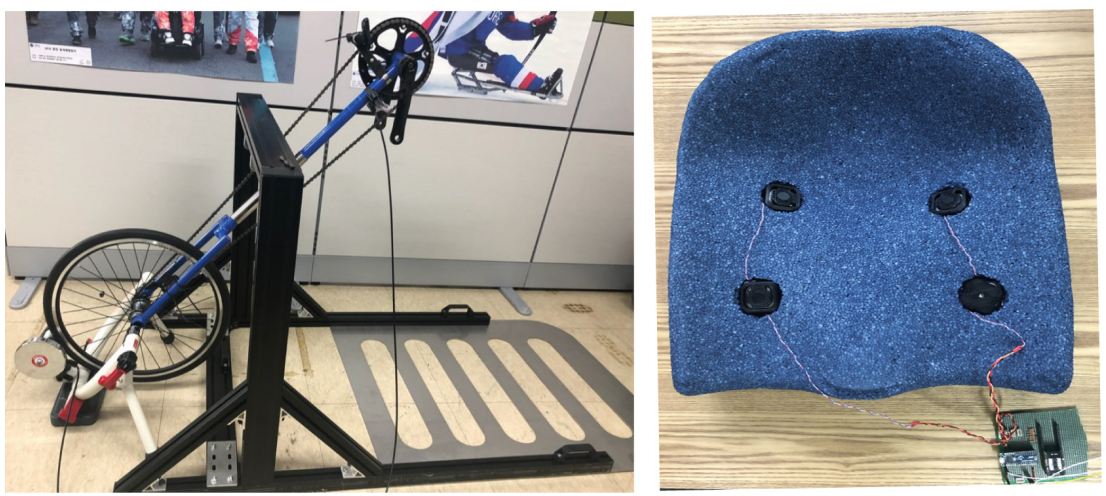

Fig. 2. Digital hand-bike and digital cushion

\section{Results}

Each intervention was evaluated with satisfaction, necessity, and difficulty, and the scale was 5 points. The results of experiments with five spinal cord injuries are as follows. Satisfaction was high at 4.8 for urinary function test and 4.4 for respiratory intervention and home visit occupational therapy. Necessity was high with interventional function test (4.4), respiratory function intervention (4.2), and home visit occupational therapy (4.2). The difficulty was not severe, all reported as 1.4 (Fig. 3).

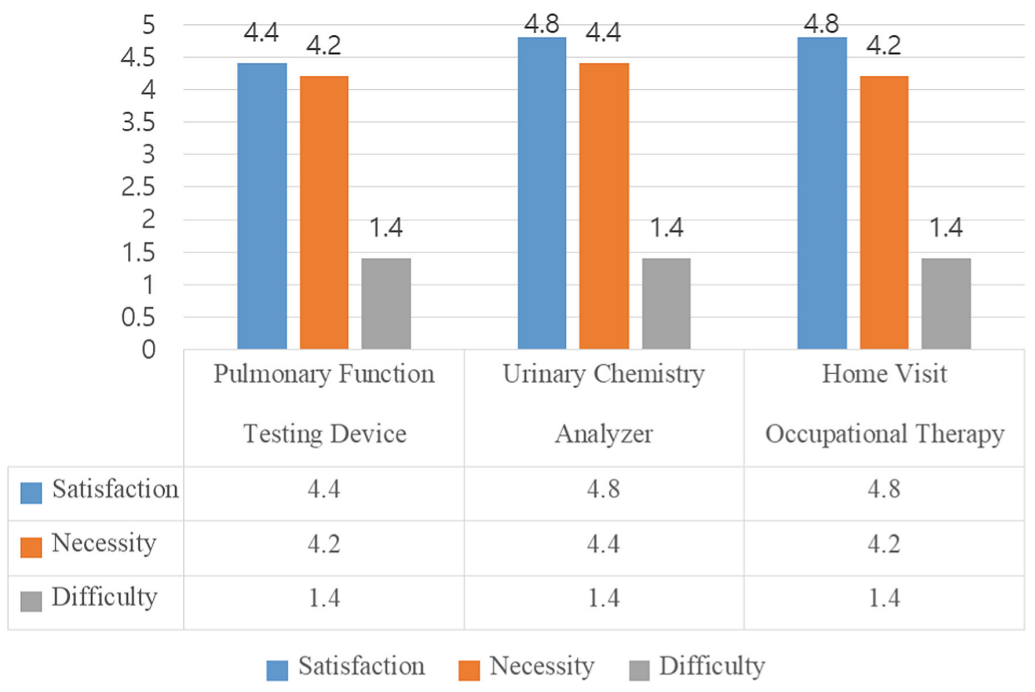

Fig. 3. Results 


\section{Conclusion}

World Health Organization (WHO) provides guidance on technologies and services for improving the health of elderly and disabled people in the community [19]. The report recommends that new technologies to be developed and serviced for medical and assistive devices should have good accessibility and usability and that they will be able to use quality and effective services at a low cost. Above all, the emphasis was placed on meeting the needs of local communities and consumers. The ICT-based health care service model for community spinal cord injuries presented in this study shows the appropriate level of satisfaction in both satisfaction and need, as shown in the study results. Based on the results of this pilot study, we recognized the need for further study and are currently preparing for the RCT clinical study. Improvements to products and services will require constant updates. In addition, we are designing exercise equipment to improve body function and developing products to prevent a pressure ulcer. If so, this service could be more helpful in health care and prevention of complications, and it can be expected to be reflected in the health insurance system.

Acknowledgments. The research was supported by a grant of the Korea Health Technology R\&D Project through the Korea Health Industry Development Institute (KHIDI), funded by the Ministry of Health \& Welfare, Republic of Korea (grant number: HI18C0552).

\section{References}

1. Liem, N.R., McColl, M.A., King, W., Smith, K.M.: Aging with a spinal cord injury: factors associated with the need for more help with activities of daily living. Arch. Phys. Med. Rehabil. 85(10), 1567-1577 (2014)

2. Nas, K., Yazmalar, L., Şah, V., Aydın, A., Öneș, K.: Rehabilitation of spinal cord injuries. World J. Orthop. 6(1), 8-16 (2015)

3. Dijkers, M.P.: Correlates of life satisfaction among persons with spinal cord injury. Arch. Phys. Med. Rehabil. 80(8), 867-876 (1999)

4. Amatachaya, S., Wannapakhe, J., Arrayawichanon, P., Siritarathiwat, W., Wattanapun, P.: Functional abilities, incidences of complications and falls of patients with spinal cord injury 6 months after discharge. Spinal Cord 49(4), 520-524 (2011)

5. Sezer, N., Akkuş, S., Uğurlu, F.G.: Chronic complications of spinal cord injury. World J. Orthop. 6(1), 24-33 (2015)

6. Jackson, A.B., Groomes, T.E.: Incidence of respiratory complications following spinal cord injury. Arch. Phys. Med. Rehabil. 75(3), 270-275 (1994)

7. McKinley, W.O., Jackson, A.B., Cardenas, D.D., Michael, J.: Long-term medical complications after traumatic spinal cord injury: a regional model systems analysis. Arch. Phys. Med. Rehabil. 80(11), 1402-1410 (1999)

8. Krueger, H., Noonan, V.K., Trenaman, L.M., Joshi, P., Rivers, C.S.: The economic burden of traumatic spinal cord injury in Canada. Chronic Dis. Injuries Can. 33(3), 113-122 (2013)

9. Korea Spinal Cord Injury Association. http://www.kscia.org/board/list/menu03_05?init

10. Hossain, M.S., et al.: A pilot randomised trial of community-based care following discharge from hospital with a recent spinal cord injury in Bangladesh. Clin. Rehabil. 31(6), 781-789 (2017) 
11. White, B.A., et al.: The economic burden of urinary tract infection and pressure ulceration in acute traumatic spinal cord injury admissions: evidence for comparative economics and decision analytics from a matched case-control study. J. Neurotrauma 34(20), 2892-2900 (2017)

12. Sechrist, S., Lavoie, S., Khong, C.M., Dirlikov, B., Shem, K.: Telemedicine using an iPad in the spinal cord injury population: a utility and patient satisfaction study. Spinal Cord Ser. Cases 4(1), 71 (2018)

13. Martinez, R.N., et al.: Sociotechnical perspective on implementing clinical video telehealth for veterans with spinal cord injuries and disorders. Telemed. e-Health 23(7), 567-576 (2017)

14. Wellbeloved-Stone, C.A., Weppner, J.L., Valdez, R.S.: A systematic review of telerehabilitation and mHealth interventions for spinal cord injury. Curr. Phys. Med. Rehabil. Rep. 4(4), 295-311 (2016)

15. Phillips, V.L., Vesmarovich, S., Hauber, R., Wiggers, E., Egner, A.: Telehealth: reaching out to newly injured spinal cord patients. Public Health Rep. 116, 94-102 (2016)

16. Tiftik, T., et al.: Does locomotor training improve pulmonary function in patients with spinal cord injury? Spinal Cord 53(6), 467-470 (2015)

17. Kim, D.I., Lee, H., Lee, B.S., Kim, J., Jeon, J.Y.: Effects of a 6-week indoor hand-bike exercise program on health and fitness levels in people with spinal cord injury: a randomized controlled trial study. Arch. Phys. Med. Rehabil. 96(11), 2033-2040 (2015)

18. Byrne, D.W., Salzberg, C.A.: Major risk factors for pressure ulcers in the spinal cord disabled: a literature review. Spinal Cord 34(5), 255-263 (1996)

19. WHO: Consultation on Advancing Technological Innovation for Older Persons in Asia. https://extranet.who.int/kobe_centre/sites/default/files/summary_report_innovation_ feb2013.pdf

Open Access This chapter is licensed under the terms of the Creative Commons Attribution 4.0 International License (http://creativecommons.org/licenses/by/4.0/), which permits use, sharing, adaptation, distribution and reproduction in any medium or format, as long as you give appropriate credit to the original author(s) and the source, provide a link to the Creative Commons license and indicate if changes were made.

The images or other third party material in this chapter are included in the chapter's Creative Commons license, unless indicated otherwise in a credit line to the material. If material is not included in the chapter's Creative Commons license and your intended use is not permitted by statutory regulation or exceeds the permitted use, you will need to obtain permission directly from the copyright holder.

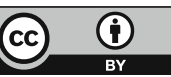

